\title{
Effect of anneal temperature on electrical and optical properties of SnS:Ag thin films
}

\author{
Hong-Jie Jia ${ }^{1}$, Shu-Ying Cheng ${ }^{1,3}$, Xin-Kun Wu ${ }^{1}$, Yong-Li Yang ${ }^{2}$ \\ ${ }^{1}$ College of Physics and Information Engineering, and Institute of Micro-Nano Devices and Solar Cells, Fuzhou University, Fuzhou, \\ China \\ ${ }^{2}$ Ministry of Education Key Laboratory of Analysis and Detection Technology for Food Safety, and Department of Chemistry, \\ Fuzhou University, Fuzhou, China \\ ${ }^{3}$ Corresponding author at: College of Physics and Information Engineering, Fuzhou University, Fuzhou, China; sycheng@, fzu.edu.cn
}

Received 14 September 2009; revised 13 January 2010; accepted 25 January 2010.

\begin{abstract}
SnS and Ag films were deposited on glass substrates by vacuum thermal evaporation technique successively, and then the films were annealed at different temperatures $\left(0-300^{\circ} \mathrm{C}\right)$ in $\mathrm{N}_{2}$ atmosphere for $2 \mathrm{~h}$ in order to obtain silver-doped SnS ( SnS:Ag ) films. The phases of SnS:Ag films were analyzed by X-ray diffraction (XRD) system, which indicated that the films were polycrystalline SnS with orthogonal structure, and the crystallites in the films were exclusively oriented along the (111) direction. With the increase of the annealing temperature, the carrier concentration and mobility of the films first rose and then dropped, whereas their resistivity and direct band gap $E_{g}$ showed the contrary trend. At the annealing temperature of $260^{\circ} \mathrm{C}$, the SnS:Ag films had the best properties: the direct bandgap was $1.3 \mathrm{eV}$, the carrier concentration was up to $1.132 \times 10^{17} \mathrm{~cm}^{-3}$, and the resistivity was about $3.1 \Omega \mathrm{cm}$.
\end{abstract}

Keywords: Sns:Ag Films; Thermal Evaporation; Annealing; Electrical And Optical Properties

\section{INTRODUCTION}

Emphasis on cost-competitive photovoltaic cells has been involved in the study of low-cost, non-toxic materials. SnS could be of interest for photovoltaic cells, since its optical energy gap of $1.3 \mathrm{eV}[1,2]$ is close to the optimum energy gap $1.5 \mathrm{eV}$ of solar cells, and it has a high absorption coefficient $\left(>10^{4} \mathrm{~cm}^{-1}\right)$ and a high conversion efficiency of about $25 \%$ [3,4]. In addition, the constituent elements $\mathrm{Sn}$ and $\mathrm{S}$ are non-toxic and abundant in nature.

In spite of the above advantages, the electrical proper- ties of SnS thin films still need to be improved in order to make good SnS thin film solar cells. W. Albers et al. [5] investigated Sb- and Ag-doped SnS single crystals and observed n-type conductivity with carrier concentration of $\sim 10^{19} \mathrm{~cm}^{-3}$ in Sb-doped SnS crystals and p-type conductivity with $\sim 10^{18} \mathrm{~cm}^{-3}$ concentration in Ag-doped $\mathrm{SnS}$ crystals. Devika et al. [6] investigated Ag-doped SnS films grown by thermal evaporation technique and observed that the resistivity of the $\mathrm{SnS}$ layers reached a minimum value of $6.98 \Omega \mathrm{cm}$ at 15 atom \% of Ag. However, some properties of $\mathrm{SnS}: \mathrm{Ag}$ thin films are unclear and waiting for further study. In particular, how the annealing temperatures affect the microstructure and physical properties of SnS:Ag thin films prepared by vacuum thermal evaporation technique has not been investigated. Therefore, in this paper we investigate the influence of annealing temperatures on the films in order to improve optical and electrical properties of $\mathrm{SnS}: \mathrm{Ag}$ thin films.

\section{EXPERIMENTAL}

$\mathrm{SnS}$ and $\mathrm{Ag}$ films were deposited on glass substrates by vacuum thermal evaporation technique successively. The thermal evaporation system is DMDE-450 deposition equipment (made in China). The $\mathrm{SnS}$ powder with $99.5 \%$ purity and the Ag grains with $99.9 \%$ purity were used as source materials and were loaded onto a ceramic crucible and a molybdenum boat, respectively. The chamber was evacuated down to $5.6 \times 10^{-3} \mathrm{~Pa}$. The source-to-substrate distance was about $10 \mathrm{~cm}$. The as-prepared films were annealed at different temperatures of 210,260 and $300^{\circ} \mathrm{C}$ in $\mathrm{N}_{2}$ atmosphere for $2 \mathrm{~h}$ respectively so that Ag-doped SnS films can be obtained.

The structure of the films was characterized by a Philips X'Pert-MPD X-ray diffraction (XRD) system with a $\mathrm{Cu} \mathrm{K}$ radiation source. The surface roughness was analyzed by a CSPM5000 Scanning Probe Microscopy (AFM), and the thickness of the films was measured by 
a Veeco Dektak 6M stylus profiler. The transmission and reflectance spectra were carried out with a Varian Cary 500 UV-VIS-NIR spectrophotometer in the range $400-$ $1600 \mathrm{~nm}$. Based on Van der Pauw method, the electrical properties were determined by a HMS-3000 Hall measurement system.

\section{RESULTS AND DISCUSSION}

\subsection{Structural Analysis}

Figure 1 (a)-(d) show the XRD patterns of the samples as-prepared and annealed at different temperatures (samples S1-S4 corresponding to unannealing, 210, 260 and $300^{\circ} \mathrm{C}$ ), respectively. It can be seen from Figure 1 (a)-(c) that all the diffraction peaks are attributed to $\mathrm{SnS}$ (JCPDS39-354) phase with orthorhombic structure. It indicates that the films are polycrystalline $\mathrm{SnS}$ with a strong $\{111\}$ preferred orientation. With the increase of the annealing temperature, the main diffraction peaks of the samples become stronger. Sample S3 exhibits the best crystallization. But the crystallization of sample $\mathrm{S} 4$ becomes weaker and there is an obvious $\mathrm{SnO}_{2}$ peak at $2 \theta$ $=33.17^{\circ}$. Maybe a partial of $\mathrm{SnS}$ was oxidized into tin dioxide $\left(\mathrm{SnO}_{2}\right)$ at the higher annealing temperature because of a low vacuum annealing condition. Therefore, when the annealing temperature is higher, there is probably a $\mathrm{SnO}_{2}$ phase in the $\mathrm{SnS}: \mathrm{Ag}$ films.
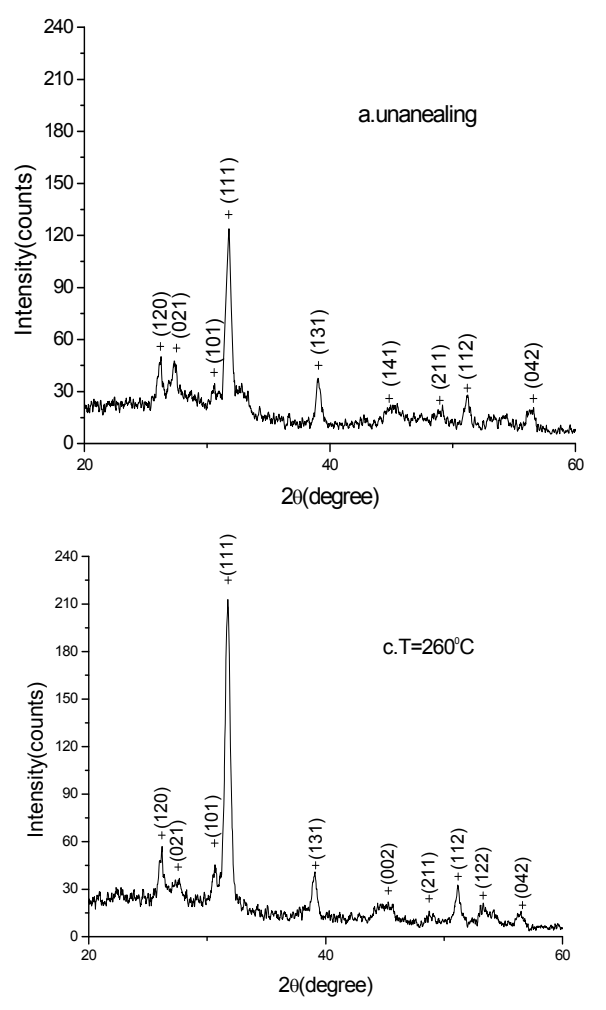

\subsection{Optical Properties}

Figure 2 shows absorption coefficient vs photon energy $(h v)$ curves of the SnS:Ag thin films at different annealing temperatures. As a whole, with the increasing of photon energy, the absorption coefficient increases rapidly and then almost stabilizes at $h v>2.5 \mathrm{eV}$. The maximum absorption coefficients of all the films are greater than $1.3 \times 10^{5} \mathrm{~cm}^{-1}$. With the increase of the annealing temperature, the absorption coefficient increases correspondingly. Because the improved crystallization and uniformity, and the reduced defect density in the films will make the scattered light loss decrease, thus leading to the increase of the absorption coefficient. However, when the annealing temperature is equal to or greater than $300^{\circ} \mathrm{C}$, the absorption coefficient decreases probably due to the presence of $\mathrm{SnO}_{2}$ in the films.

Figure 3 shows a curve of $(\alpha h v)^{2}$ vs. $h v$ for sample S3 and the estimated $E \mathrm{~g}$ value of $1.30 \mathrm{eV}$ (here only show sample S3 for simplicity). The $E g$ values of all the four samples are shown in Table 1. With the increase of the annealing temperature, the $E_{g}$ first drops and then rises. Because, with the increasing of the annealing temperature, $\mathrm{Ag}$ atoms are easier to be diffused and doped in the polycrystalline $\mathrm{SnS}$ films, and the doped-Ag can drop the band gap [6]. But the $E g$ value of sample S4 is larger than that of sample $\mathrm{S} 3$, this is perhaps due to the presence of $\mathrm{SnO}_{2}(3.4 \sim 4.6 \mathrm{eV})$ [7] in sample S4.
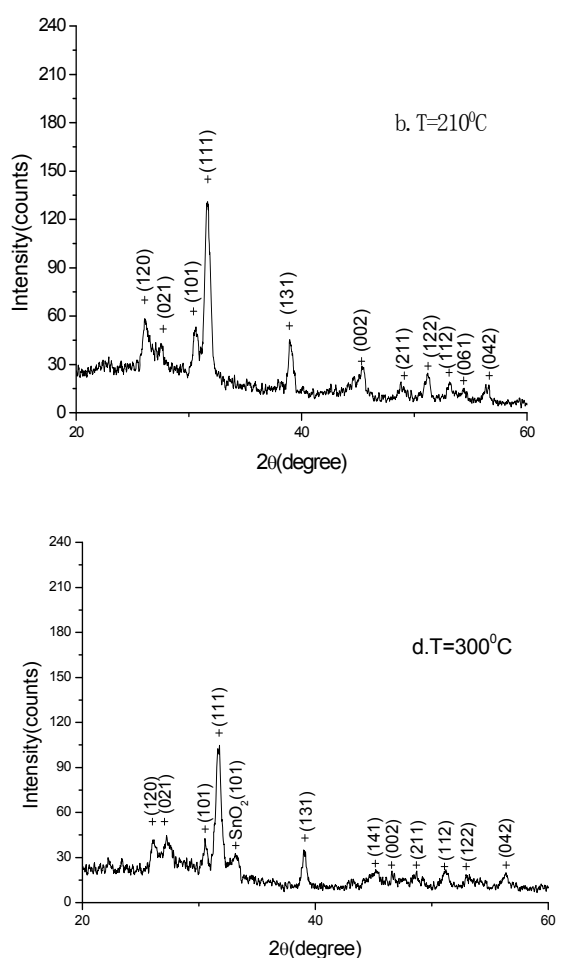

Figure 1. XRD patterns of $\mathrm{SnS}: \mathrm{Ag}$ thin films at different annealing temperatures. 
Table 1. The bandgap and absorption edge of SnS:Ag thin films at different annealing temperatures.

\begin{tabular}{cccc}
\hline Samples & Annealing Temperature $/{ }^{\circ} \mathrm{C}$ & Band gap Eg $/ \mathrm{eV}$ & Absorption Edge $/ \mathrm{nm}$ \\
\hline S1 & unannealed & 1.34 & 925.4 \\
S2 & 210 & 1.32 & 939.4 \\
S3 & 260 & 1.30 & 953.8 \\
S4 & 300 & 1.52 & 815.8 \\
\hline
\end{tabular}

Table 2. Hall measurement results for SnS:Ag thin films at different annealing temperatures.

\begin{tabular}{cccccc}
\hline Samples & temperature ${ }^{\circ} \mathrm{C}$ & Bulk concentration $/ \mathrm{cm}^{-3}$ & $\begin{array}{c}\text { Mobility/ } \\
\left(\mathrm{cm}^{2} \cdot \mathrm{v}^{-1} \cdot \mathrm{s}^{-1}\right)\end{array}$ & $\begin{array}{c}\text { Resistivity/ } \\
(\Omega \mathrm{cm})\end{array}$ & $\begin{array}{c}\text { Average Hall Coeffi- } \\
\text { cient } /\left(\mathrm{m}^{2} \mathrm{c}^{-1}\right)\end{array}$ \\
\hline S1 & unannealed & $7.242 \times 10^{14}$ & 14.3 & 601.1 & $8.631 \times 10^{3}$ \\
S2 & 210 & $3.212 \times 10^{16}$ & 16.3 & 11.9 & $1.945 \times 10^{2}$ \\
S3 & 260 & $1.132 \times 10^{17}$ & 17.8 & 3.1 & $5.522 \times 10^{1}$ \\
S4 & 300 & $2.601 \times 10^{16}$ & 15.7 & 15.3 & $2.402 \times 10^{2}$ \\
\hline
\end{tabular}

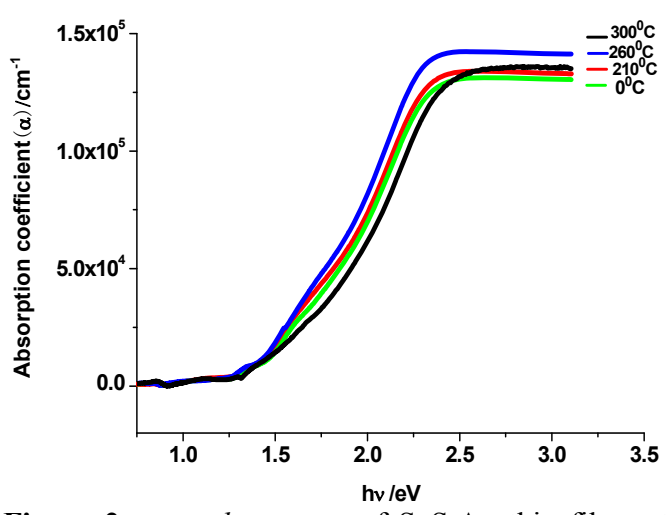

Figure 2. $\alpha$ vs. $h v$ curves of $\mathrm{SnS}: \mathrm{Ag}$ thin films at different annealing temperatures.

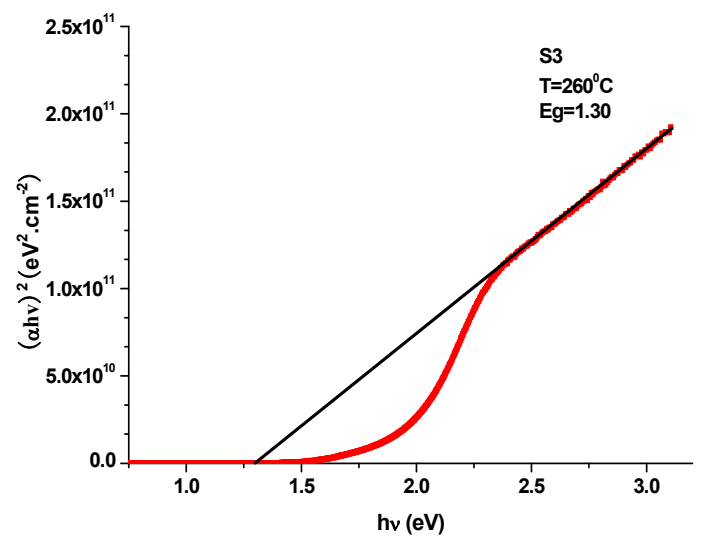

Figure 3. $(\alpha h v)^{2}$ vs. $h v$ curve of the $\mathrm{SnS}: \mathrm{Ag}$ thin film annealed at $260^{\circ} \mathrm{C}$.

\subsection{Electrical Properties}

At room temperature, semiconducting properties of the films were measured by a HMS-3000 Hall measurement system. The results are listed in Table 2. Compared with the unannealed sample, the semiconducting properties of the annealed samples have been improved. With the increase of the annealing temperature, the carrier concentration and mobility increase whereas the resistivity decreases except that of films annealed at $300^{\circ} \mathrm{C}$. When the annealing temperature equals to $260{ }^{\circ} \mathrm{C}$, the carrier con- centration and mobility reach the maximum values of $1.132 \times 10^{17} \mathrm{~cm}^{-3}$ and $17.8 \mathrm{~cm}^{2} \cdot \mathrm{v}^{-1} \cdot \mathrm{s}^{-1}$, respectively. But, when the annealing temperature is up to $300^{\circ} \mathrm{C}$, the carrier concentration decreases to $2.601 \times 10^{16} \mathrm{~cm}^{-3}$ with a mobility of $15.7 \mathrm{~cm}^{2} \cdot \mathrm{v}^{-1} \cdot \mathrm{s}^{-1}$. The phenomenon can be explained by the fact that, with the increase of the annealing temperature, better crystallization and greater grain size in the films lead to the decrease of defects density and crystal-boundary, therefore the resistivity decreases. However, higher temperature urges crystal lattice vibration stronger and results in some crystal lattice defects. These defects become dispersion centers, causing the increase of resistivity of the films. In addition, the presence of $\mathrm{SnO}_{2}$ can also cause the resistivity of the films increasing. Notably, the average Hall coefficients of all the samples are positive, which proves that the SnS:Ag films are of p-type conduction.

\section{CONCLUSIONS}

The SnS:Ag thin films were deposited on glass substrates using thermal evaporation technique and postannealing, and effect of annealing on the films was investigated. The above results indicate that appropriate annealing temperature can increase the grain size of the films, improve the uniformity and crystallization of the films, decrease the resistivities of the films, and increase the absorption coefficients of the films. However, if the annealing temperature is higher than $300^{\circ} \mathrm{C}$, crystallization of the films become weaker and the films can be oxidized due to low vacuum, thereby electrical and optical properties of the films become poor. At an annealing temperature of $260^{\circ} \mathrm{C}$, the SnS:Ag films have the best properties: the direct bandgap is $1.3 \mathrm{eV}$, the carrier concentration is up to $1.132 \times 10^{17} \mathrm{~cm}^{-3}$, and the resistivity is about $3.1 \Omega \mathrm{cm}$.

\section{ACKNOWLEDGMENT}

The project-sponsored by SRF for ROCS, SEM (LXKQ0801) is gratefully acknowledged. The authors also wish to express their gratitude to 
funding from Fujian Provincial Department of Science \& Technology and Department of Education, China (2008I0019, 2009J01285, JB09008, JB09010)

\section{REFERENCES}

[1] El-Nahass, M.M., Zeyada, H.M., Aziz, M.S., et al. (2002) Optical properties of thermally evaporated $\mathrm{SnS}$ thin films [J]. Optical Materials, 20, 159-170.

[2] Devika, M., Koteeswara Reddy, N., Sreekantha Reddy, D., et al. (2008) Synthesis and characterization of nanocrystalline $\mathrm{SnS}$ films grown by thermal evaporation technique [J]. Journal of the Electrochemical Society, 155, 130-135.

[3] Takeuchi, K., Ichimura, K.M., Arai, M.E., et al. (2003) $\mathrm{SnS}$ thin films fabricated by pulsed and normal electro chemical deposition [J]. Solar Energy Material and Solar
Cells, 75, 427-432.

[4] Muller R. S. (1991) Microsensor [M]. The Institute of Electrical and Electronics Engineers Inc, New York.

[5] Albers, W., Hass, C., Vink, H.J., et al. (1961) Investigations on $\mathrm{SnS}[\mathrm{J}]$. Applied Physics, 32(10), 2220-2225.

[6] Devika, M., Koteeswara, R.N., Ramesh, K., et al. (2006) Low resistive micrometer-thick SnS:Ag films for optoelectronic applications [J]. Journal of the Electrochemical Society, 153,727-733.

[7] Yakuphanoglu, F. (2009) Electrical conductivity, Seebeck coefficient and optical properties of $\mathrm{SnO}_{2}$ film deposited on ITO by dip coating [J]. Journal of Alloys and Compounds, 470, 55-59. 